Journal of Social Sciences 7 (3): 364-368, 2011

ISSN 1549-3652

(C) 2011 Science Publications

\title{
A Preliminary Study on Choosing Sports Tourism as a Leisure Time Option
}

\author{
Maura Stancu \\ Department of Sport Games, Faculty of Physical Education and Sport, \\ University of Pitesti
}

\begin{abstract}
Problem statement: It has long been acknowledged that, when speaking about sports tourism, we must consider, on one side, tourism-an economic and social phenomenon that is specific to modern civilization and on the other side sports-the most widely spread social phenomenon in the world. No other events had such a complex unfolding than sports events, and tourism had undoubtedly become one of the world's greatest industries. Our assumption was that physical education and sports teachers have successfully contributed to the accomplishment of objective of "forming the habit of practicing physical exercise for recreational, emulative and compensatory purposes throughout the life span". Approach: To test this assumption we have initiated a sociological research: A questionnaire was applied on a sample of 50 persons. Collected data were analyzed using descriptive and inferential procedures. Results: The results allowed the confirmation of stated research hypotheses. We have shown that practicing a performance sport is significantly related with preference for risk, adventure tourism (Chi-square $=6,614$, d.f. $=1, p=0,010$ ). Conclusions: Citizen's option for sports tourism activities were shown to be relevant for physical education and sports teachers, in order to better organize their activities.
\end{abstract}

Key words: Tourism activities, statistically significant, social phenomenon, performance sport, physical education, research hypotheses, physical exercise

\section{INTRODUCTION}

Tourism is an area of growing importance in contemporary times, becoming an economic and social phenomenon specific to modern civilization. For us, professionals in the field, practicing physical exercises in the form of tourism may be a confirmation that an important objective of physical education, "forming the habit of practicing physical exercise for recreational, emulative and compensatory purposes throughout the life span", is fulfilled.

For the citizen that chooses to practice sports tourism, among the multitude of existing forms of tourism (ecumenical, entertainment, recreational and treatment, for shopping, scientific, rural, bird-watching, forest-tourism), the physical exercise that is being practiced can become a complex activity, with numerous learning opportunities (in the biological, geographical, historical, ethnographic fields).

In addition, the way we promote different physical activities using tourism leads to new opportunities for socialization, for communication, for enhancing man's abilities to reintegrate in the natural environment (lighting a fire, camping, spatial orientation using a map and a compass), for the psychomotor development of the subjects (corporal schema, dynamic coordination, lateralization, equilibrium, speed), for their ecological education (SeifolddiniFaranak et al., 2009; Corti et al., 2010; Gangopadhyay et al., 2011; Vazakidis and Adamopoulos, 2010; Yassin et al., 2010).

Physical exercise that is practiced in nature in the form of sports tourism activates all the senses and enriches the experience of the individual, putting to action mind, soul and body altogether.

Motivation is the answer to why people choose to practice or not sports tourism. And us, teachers of physical education and sport, are also the ones responsible for the successful development of the motivation related to sports tourism.

\section{MATERIALS AND METHODS}

Aim of research: The aim of our research is to find out how interested our subjects are in spending their freetime in the middle of nature, practicing sports tourism activities and what is the reason that drives them towards this option.

Research hypotheses: In this research we have stated three hypotheses.

Hypothesis 1: A high level of personal dynamism is a basic condition for practicing leisure time sport activities. 


\section{J. Social Sci., 7 (3): 364-368, 2011}

Hypothesis 2: Men, more than women, choose to practice different sports even during their trips to the mountains or to the seaside.

Hypothesis 3: If our subjects have formed the habit of systematically and consciously practicing physical exercises, then they will tend more than other persons to choose active forms of tourism, including risk, adventure tourism.

Subjects: Considering the results of the 2002 population census for Pitesti city and the data on forms of tourism classified by age categories and occupation, data provided by Tourism Economics, we have questioned a total number of 50 citizens, distributed as follows: 20 citizens, both men and women, aged 18/1934 years old (belonging to the "young age tourists" category); 25 citizens, both men and women, aged 3564 years old-considered to be part of the "active population" (belonging to the "middle-age tourists" category); 5 citizens, pensioners, aged 65 years old or above (belonging to the "old age tourism" category). Our sample was a representative one as far as age categories are concerned (the distribution of the age variable for our sample corresponded to the distribution of age for the entire population over 18 years old from Pitesti city).

Methods: The research methods employed in this study are: Observation, scientific documentation, questionnaire-based inquiry, graphic and statistical methods.

Data gathering: As tourism has flourished in contemporary times, becoming an economic and social phenomenon that has multiple consequences, we have thought it would be also good to know where exactly do we stand as far as this matter of sports tourism is concerned; this fact guided us towards this research, a research that involved the following working stages:

- The study of the official documents published after the last population census

- Sampling

- The development of the questionnaire, pilot-testing it and conducting the final inquiry, having as substages: instructing the field operators and organizing the collection of data

\section{RESULTS}

For this study we have conceived a questionnaire consisting of 12 questions referring to:
- The socio-demographic characteristics of the respondents

- Their involvement in activities specific to sports tourism and related preferences and habits

Collected data were verified, coded and statistically analyzed using the SPSS for Windows (version 10) software. Presented below are the statistical analysis and the interpretation of data.

Using descriptive statistics procedures, we have analyzed a number of socio-demographic characteristics of the respondents; also, 12 questions referred to their involvement in activities specific to sport and sports tourism, their subjective preferences and habits.

Inferential statistics procedures were used to test our research hypotheses.

Hypothesis 1 stated that: "A high level of personal dynamism is a basic condition for practicing leisure time sport activities". As it was expected, people that target doing sports during their trips tend to have a level of dynamism medium or above medium-as opposed to the ones that look for rest and that may also have low or very low levels of personal dynamism; plus, none of these people rated their dynamism level as very high. The relation between a person's dynamism and the goals he / she targets during trips is statistically significant $($ Chi-square $=19,853$, d.f. $=4, p=0,001)$; data discussed here are detailed in Table 1.

The respondents that prefer to practice aquatic sports at the seaside tend to have a level of dynamism medium or above medium - as opposed to the ones that choose to stay on the beach and rest (and that can have low or very low levels of personal dynamism; plus, none of those rated their dynamism level as very high). The relation between the level of dynamism and personal preferences during trips to the seaside is statistically significant (Chi-square $=124,022$, d.f. $=4$, $\mathrm{p}<0,001$ ); data discussed here are detailed in Table 2.

Similarly, the respondents that prefer to practice mountain sports at the mountains tend to have a level of dynamism medium or above medium (just one of these persons rated the personal level of dynamism as being low) - as opposed to the ones that prefer barbecue at river's edge and just relaxing (and that can have low or very low levels of personal dynamism; plus, just one of those persons rated the personal level of dynamism as very high). The relation between the level of dynamism and personal preferences during trips to the mountains is statistically significant (Chi-square $=10,317$, d.f. $=4$, $\mathrm{p}=0,035)$; data discussed here are detailed in Table 3. 


\section{J. Social Sci., 7 (3): 364-368, 2011}

Table 1: The relation between personal dynamism and the goals targeted during trips

\begin{tabular}{|c|c|c|c|c|c|c|c|}
\hline & & \multicolumn{5}{|c|}{ Dynamism } & \multirow[b]{2}{*}{ Total } \\
\hline & & Very low & Low & Medium & High & Very high & \\
\hline \multirow[t]{2}{*}{ Goal of going out } & Rest & 2 & 7 & 12 & 9 & 0 & 30 \\
\hline & Sport & 0 & 0 & 4 & 8 & 8 & 20 \\
\hline Total & 2 & 7 & 16 & 17 & 8 & 50 & \\
\hline
\end{tabular}

Table 2: The relation between personal dynamism and sport preferences during trips to the seaside

\begin{tabular}{|c|c|c|c|c|c|c|c|}
\hline & & \multicolumn{5}{|c|}{ Dynamism } & \multirow[b]{2}{*}{ Total } \\
\hline & & Very low & Low & Medium & High & Very high & \\
\hline At the seaside & Relaxation & 2 & 7 & 14 & 9 & 0 & 32 \\
\hline you prefer & Sport & 0 & 0 & 2 & 8 & 8 & 18 \\
\hline Total & 2 & 7 & 16 & 17 & 8 & 50 & \\
\hline
\end{tabular}

Table 3: The relation between personal dynamism and sport preferences during trips to the mountains

\begin{tabular}{|c|c|c|c|c|c|c|c|}
\hline & & \multicolumn{5}{|c|}{ Dynamism } & \multirow[b]{2}{*}{ Total } \\
\hline & & Very low & Low & Medium & High & Very high & \\
\hline At the mountain & Sport & 0 & 1 & 9 & 9 & 7 & 26 \\
\hline you prefer & Relaxation & 2 & 6 & 7 & 8 & 1 & 24 \\
\hline Total & 2 & 7 & 16 & 17 & 8 & 50 & \\
\hline
\end{tabular}

Table 4: The relation between gender and preference for leisure time sport activities

\begin{tabular}{lllll}
\hline & & & \\
& & Goal of going out & \\
& & Rest & Sport & Total \\
\hline Gender & Male & 7 & 15 & 22 \\
& Female & 23 & 5 & 28 \\
Total & & 30 & 20 & 50 \\
\hline
\end{tabular}

Table 5: The relation between gender and preference for sport activities during trips

\begin{tabular}{lllll}
\hline & & & \\
& & At the seaside you prefer & \\
& & Relaxation & Sport & Total \\
\hline \multirow{2}{*}{ Gender } & Male & 9 & 13 & 22 \\
& Female & 23 & 5 & 28 \\
Total & 32 & 18 & 50 \\
\hline
\end{tabular}

Table 6: The relation between gender and preference for sport activities during trips to the mountains

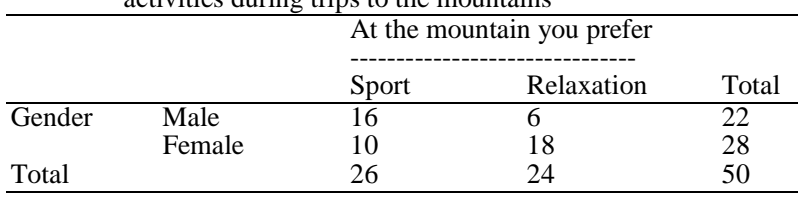

Our second research hypothesis stated that: "Men, more than women, choose to practice different sports even during their trips to the mountains or to the seaside". As expected, a pronounced tendency to choose sports tourism was noted in men. Over two thirds of the male respondents have chosen sport instead of relaxing (15 persons, compared to 7), while the majority of female respondents have chosen rest instead of practicing sport (23 persons, compared to 5). The difference between men and women is statistically significant (Chi-square $=13,001$, d.f. $=1, \mathrm{p}<0,001$ ); data discussed here are detailed in Table 4.
Most of the men stated that at the seaside they prefer sports instead of relaxing (13 persons, compared to 9), while most of the women prefer to rest instead of doing sport (23 persons, compared to 5). The difference is statistically significant (Chi-square $=9,091$, d.f. $=1, \mathrm{p}$ $=0,003$ ); data discussed here are presented in Table 5 .

At the mountains men also prefer sports instead of relaxing (16 persons, compared to 6), while most of the women prefer to rest instead of doing sport (18 persons, compared to 10). The difference between the two genders is statistically significant (Chi-square = $6,762$, d.f. $=1, p=0,009)$; data discussed here are presented in Table 6.

Our third hypothesis stated that: "If our subjects have formed the habit of systematically and consciously practicing physical exercises, then they will tend more than other persons to choose active forms of tourism, including adventure tourism. Obtained data also support this assumption. Thus, practicing a performance sport is significantly associated with the option for sports tourism activities (Chi-square = $14,286$, d.f. $=1, \mathrm{p}<0,001)$. Out of the 15 respondents that have practiced / practice a performance sport, 12 say that the motive for going to trips is their wish to do a lot of movement. In opposition, out of the 35 respondents that have not practiced / do not practice a performance sport, 27 prefer resting, relaxing when going to a trip. Data discussed here are presented in the Table 7 and Fig. 1.

Similarly, practicing a performance sport is significantly associated with the option for practicing aquatic sports at the seaside (Chi-square $=18,006$, d.f. $=1, \mathrm{p}<0,001)$. This result is illustrated in the Fig. 2 . 


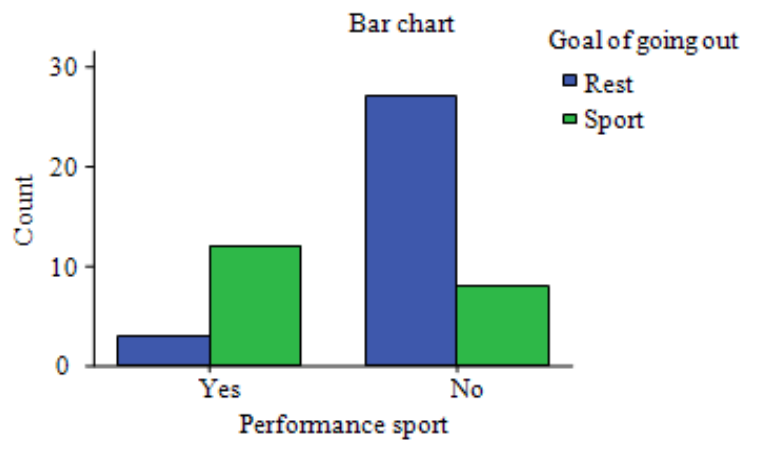

Fig. 1: Graphical representation of the relation between practicing a performance sport and the option for sports tourism activities

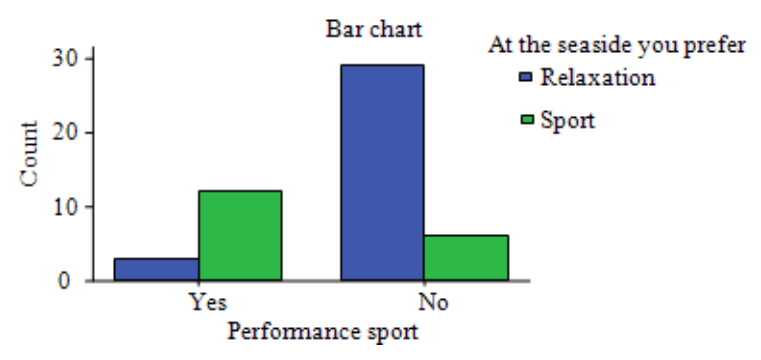

Fig. 2: Graphical representation of the relation between practicing a performance sport and the option for aquatic sports

Table 7: The relation between practicing a performance sport and the option for sports tourism activities

\begin{tabular}{lllll}
\hline \multicolumn{5}{c}{ option for sports tourism activities } \\
& & Performance sport & \\
& & Yes & No & Total \\
\hline Goal of & Rest & 3 & 27 & 30 \\
going out & Sport & 12 & 8 & 20 \\
Total & 15 & 35 & 50 & \\
\hline
\end{tabular}

Table 8: The relation between practicing a performance sport and the option for adventure tourism

\begin{tabular}{lllll}
\hline & & \multicolumn{2}{c}{ Choosing adventure sports } \\
& & Yes & No & Total \\
\hline Performance sport & Yes & 4 & 11 & 15 \\
& No & 1 & 34 & 35 \\
Total & 5 & 45 & 50 & \\
\hline
\end{tabular}

Also, practicing a performance sport is significantly associated with the option for practicing mountain sports (Chi-square $=10,317$, d.f. $=1, \mathrm{p}=$ $0,001)$. Out of the 15 respondents that have practiced / practice a performance sport, 13 say that during their trips to the mountains they prefer to practice mountain sports. In opposition, out of the 35 respondents that have not practiced/do not practice a performance sport, 22 prefer resting, relaxing, barbecue when they are at the mountains.

Practicing a performance sport is also significantly associated with a preference for risk, adventure tourism (Chi-square $=6,614$, d.f. $=1, p=0,010)$. Out of the five respondents that said they have chosen or would choose to practice adventure sports, four have practiced or practice a performance sport. Data discussed here are presented in the Table 8 .

\section{DISCUSSION}

The present study was conducted on a sample of 50 persons of different ages, both men and women. The analysis of the responses to the questionnaire has outlined the following results:

- Most of the subjects rate their dynamism level as medium $(32 \%)$ or high $(34 \%)$; eight respondents $(16 \%)$ have a very high self-assessed dynamism level and $9(18 \%)$ have a low or very low dynamism level

- Almost one third of the subjects (15 persons, representing 30\%) have practiced a performance sport

- Most of the respondents (45 persons, representing 90\%) said that they like to organize trips on their own; only eight of the respondents seek advice from a travel agency

- Most of the respondents prefer to go out to the mountains $(52 \%)$ or to the seaside (36\%); only six respondents prefer visits or trips to the relatives

- $60 \%$ of the respondents say that during those trips they seek to get rest; the rest of $40 \%$ choose trips as a way to do a lot of movement (sport)

- $64 \%$ of the respondents say that at the seaside they prefer to stay at the beach (to relax) and 36\% say they prefer to practice aquatic sports (thus, sports tourism)

- A slightly different situation is meet when analyzing trips to the mountains; $52 \%$ of the respondents prefer to practice mountain sports and $48 \%$ prefer to relax (rest, barbecue at river's edge)

- Asked whether they would choose (if they have not already chosen) to practice an adventure sport, only five $(10 \%)$ of the respondents gave an affirmative answer

- The respondents choose trips for the following reasons (motives are cited here in the order of their frequency): to be with friends (36\%); to get away from the daily routine (34\%); as a way to go back to nature (26\%); out of the adventure need (4\%). None of the respondents has chosen the documentation or research" response option 


\section{CONCLUSION}

We assert that choosing tourism in general and choosing to practice sports tourism activities in particular reflect in a synthetic manner the level of life quality.

We may also conclude that the habit of systematically practicing physical exercises may be a guarantee for the fact that citizens of different ages chose sports tourism activities in their leisure time. Practicing a performance sport is significantly associated with the option for practicing mountain sports and is also significantly associated with a preference for risk, for adventure tourism.

\section{REFERENCES}

Seifolddini-Faranak, S.M. Fard and H. Ali, 2009. Distribution and determining of tourist attractions and modeling of tourist cities for the city of Isfahan-Iran. Am. J. Econ. Bus. Admin., 1: 160166. DOI: 10.3844/ajebasp.2009.160.166
Corti, I.N., P.N. Marola and M.B. Castro, 2010. Social inclusion and local development through european voluntourism: A case study of the project realized in a neighborhood of morocco. Am. J. Econ. Bus. Admin., 2: 221-231. $\quad$ DOI: 10.3844/ajebasp.2010.221.231

Gangopadhyay, P., N. Elkanj and M.A. Rahman, 2011. Application of theories of complexity and chaos to economic misgovernance. J. Math. Stat., 7: 239248. DOI: $10.3844 / \mathrm{jmssp} .2011 .239 .248$

Vazakidis, A. and A. Adamopoulos, 2010. A causal relationship between financial market development and economic growth. Am. J. Applied Sci., 7: 575583. DOI: $10.3844 /$ ajassp.2010.575.583

Yassin, S.M., H.A.M. Shaffril, M.S. Hussain, M.S. Othman and A.A. Samah et al., 2010. Prospects of waterway development as a catalyst to improve regional and community socio-economy level. Am. J. Econ. Bus. Admin., 2: 240-246. DOI: $10.3844 /$ ajebasp.2010.240.246 